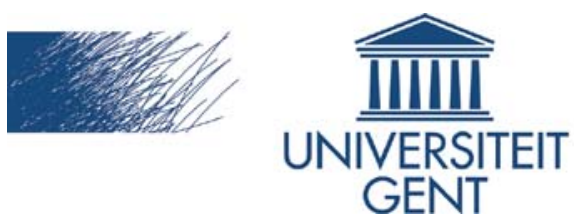

biblio.ugent.be

The UGent Institutional Repository is the electronic archiving and dissemination platform for all UGent research publications. Ghent University has implemented a mandate stipulating that all academic publications of UGent researchers should be deposited and archived in this repository. Except for items where current copyright restrictions apply, these papers are available in Open Access.

This item is the archived peer-reviewed author-version of:

Comparison of the renewable transportation fuels, hydrogen and methanol formed from hydrogen, with gasoline - Engine efficiency study

Vancoillie, J.; Demuynck, J. ; Sileghem, L.; Van de Ginste, M.; Verhelst, S.

In: International Journal of Hydrogen Energy, 37 (12), 9914-9924, 2012.

http://dx.doi.org/10.1016/j.ijhydene.2012.03.145

To refer to or to cite this work, please use the citation to the published version:

Vancoillie, J. et al. (2012). Comparison of the renewable transportation fuels, hydrogen and methanol formed from hydrogen, with gasoline - Engine efficiency study. International Journal of Hydrogen Energy 37(12) 9914-9924. Doi: 10.1016/j.ijhydene.2012.03.145 


\title{
Comparison of the renewable transportation fuels, hydrogen and methanol formed from hydrogen, with gasoline - Engine efficiency study
}

\author{
J. Vancoillie, J. Demuynck, L. Sileghem, M. Van De Ginste, S. Verhelst \\ Ghent University, Department of Flow, Heat and Combustion Mechanics, \\ Sint-Pietersnieuwstraat 41 B-9000 Gent, Belgium
}

\begin{abstract}
The use of hydrogen derived methanol in spark-ignition engines forms a promising approach to decarbonizing transport and securing domestic energy supply. Methanol can be renewably produced from hydrogen in combination with biomass or $\mathrm{CO}_{2}$ from the atmosphere and flue gases. From well to tank studies it appears that hydrogen derived methanol compares favourably with liquid or compressed hydrogen both in terms of production cost and energy efficiency. Since existing well to wheel studies are based on outdated technology, this paper tries to provide efficiency figures for state-of-the-art hydrogen and methanol engines using published data and measurements on our own flex-fuel engine.

Both fuels offer a great potential for efficiency improvements compared to gasoline engines thanks to a variety of favourable properties. However, there is a clear distinction between engines specifically designed for hydrogen or methanol operation and flex-fuel engines, which should also run on gasoline. For dedicated engines, the literature indicates that peak brake thermal efficiencies up to $45 \%$ and $42 \%$ are possible on hydrogen and methanol respectively. The ability to employ qualitative load control instead of throttling enables relative efficiency improvements compared to gasoline between 10-20\% due to reduced pumping losses in part load. On our flex fuel engine, operation on hydrogen using qualitative load control enabled the highest efficiencies, especially at low loads, where improvements up to $40 \%$ relative to gasoline were possible. At elevated loads, rising $\mathrm{NO}_{\mathrm{x}}$ emissions necessitated a switch to throttled stoichiometric operation, resulting in efficiencies comparable to those on gasoline. The efficiency benefit of methanol is more modest
\end{abstract}

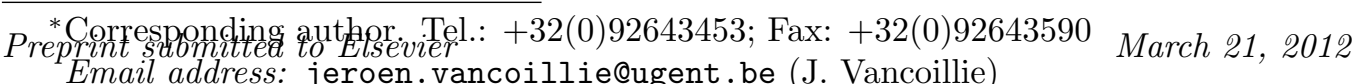


(5-10\% relative to gasoline), but can be retained over the entire load range. These improvements are mostly due to reduced pumping losses, increased burning velocities and a slight decrease in cooling losses.

Future well-to-wheel studies should take this considerable potential for efficiency improvements into consideration and should also distinguish between dedicated and flex-fuel engines.

Keywords: spark-ignition engine, hydrogen, methanol, gasoline, efficiency, emissions

\section{Introduction}

\subsection{Renewable transportation fuels}

Our present energy supply is based on fossil fuels, which are depletable. Given the growing world population, increasing energy demand per capita and global warming, the need for a long-term alternative energy supply is clear. This is particularly true for the transport sector, which is extremely dependent on oil. Although transport is currently only the third largest contributor to energy use and greenhouse gas emissions, it is the fastest growing sector.

Battery electric vehicles (BEVs) and hydrogen fuelled fuel cell electric vehicles (FCEVs) are two approaches to de-carbonizing transport that receive a lot of attention these days. Their advantages include very high tank to wheel efficiencies and zero local noxious and greenhouse gas (GHG) emissions. Their net GHG emissions, however, depend on the upstream energy supply.

Today's batteries are fundamentally limited by their energy density. To match the range of a conventional gasoline vehicle with a 50 litre fuel tank using the current battery technology would require $600-1000 \mathrm{~kg}$ of batteries with a total cost between $\$ 25000$ and $\$ 80000$ [1]. It is questionable if the costumer will accept these additional costs, especially since the majority of growth in transport is expected in countries with developing economies [2].

60 Hydrogen comfortably exceeds batteries in terms of on-board energy density, but is rather low compared to liquid fuels. Also, the liquefaction or compression of hydrogen do require considerable amounts of energy $(40 \%$ and $20 \%$ of the higher heating value respectively [3]) and renewable production of hydrogen through electrolysis of water is an energy intensive process 65 [4]. 
Affordable fuel cells still seem a long way off [5]. Fortunately, hydrogen can also be used in spark-ignition (SI) engines at low cost, high efficiency and with a number of other benefits, of which the most practical one is the ability to run in flex-fuel operation [6]. Still, the inherently low energy density and high associated infrastructure costs make it unlikely that hydrogen will become competitive with liquid fuels for transportation purposes in the near future.

An interesting alternative is employing renewable hydrogen to produce methanol. Methanol is the simplest organic hydrogen carrier that is liquid atmospheric conditions. This facilitates storage on-board a vehicle and entails the important advantage that existing infrastucture for liquid fuels can be largely retained. Just as hydrogen, methanol can be used in flex-fuel or dedicated SI engines with high efficiencies and low emissions compared to gasoline [1]. Additionally, methanol can be added to ternary mixtures with gasoline and ethanol, which can help to expedite a gradual transition toward carbon-neutral fuels.

\subsection{Hydrogen versus hydrogen derived methanol: well-to-tank study}

The production of renewable methanol from hydrogen requires a sustainable carbon source. This can be provided either by biomass or by $\mathrm{CO}_{2}$ extracted from flue gases (e.g. from fossil fuel-fired power plants) and the atmosphere. Both options have been the subject of several excellent review papers focusing on the feasibility, energetic and economic aspects $[1,4,7,8]$.

The use of biomass gasification requires addition of hydrogen in order to get syngas with the optimal $\mathrm{H}_{2}$ to $\mathrm{CO}$ ratio for methanol synthesis $(>2[1,8])$. According to Specht and Bandi [9] well to wheel GHG reductions of almost $90 \%$ compared to gasoline are possible using methanol from biomass. Several studies indicate that renewable methanol made in this way would cost about $€ 400$ /tonne, which is approximately $50 \%$ more expensive than $\$ 65 /$ barrel (anno 2009) gasoline on an equivalent energy basis [1, 10, 11, 8]. Hydrogen production through electrolysis is the main factor defining the cost [1]. The reported well to tank efficiencies for this process are about 51\% (related to the lower heating value of methanol). For liquified hydrogen and gasoline this becomes $57.7 \%$ and $89.6 \%$ respectively [11].

Because the production of biomass is limited by the amount of arable land, competition with food crops, etc, biofuels can only constitute part of our energy supply (27\% globally according to Bandi and Specht [12]). This biomass limit can be exceeded by producing methanol directly from $\mathrm{CO}_{2}$ 
using heterogeneous catalytic hydrogenation of carbon dioxide:

$$
\mathrm{CO}_{2}+3 \mathrm{H}_{2} \rightarrow \mathrm{CH}_{3} \mathrm{OH}+\mathrm{H}_{2} \mathrm{O}
$$

In the same way that biofuels recycle carbon biologically, artificial carbon recycling can be envisaged by extracting $\mathrm{CO}_{2}$ from the atmosphere and producing methanol from it. Alternatively, more concentrated $\mathrm{CO}_{2}$ can be captured from flue gases of fossil fuel-fired power plants, cement factories, fermentation processes and water purification plants [8]. This carbon recycling concept has been proposed by a number of workers and dates back over 30 years $[4,13,14,15,16,17]$.

Interestingly, methanol can also form a chemical feedstock for the manufacture of plastics, paints and synthetic hydrocarbons through the application of the methanol-to-olefins process [17]. In this way, the production of methanol from renewable hydrogen and atmospheric $\mathrm{CO}_{2}$ can form the basis of a true methanol economy, in which carbon dioxide is no longer a detrimental greenhouse gas, but a renewable carbon source allowing environmentally neutral use of carbon fuels and derived hydrocarbon products [17].

Critical issues for the further development of this cycle are the investment in $\mathrm{CO}_{2}$ extraction and regeneration infrastructure, further development of high-performance, robust and inexpensive catalysts for methanol synthesis and the availability and cost of renewable hydrogen $[4,7]$.

Methanol made from atmospheric $\mathrm{CO}_{2}$ would be almost carbon neutral, since all $\mathrm{CO}_{2}$ emissions during the production process would be offset by $\mathrm{CO}_{2}$ removed from the atmosphere [9]. Several studies indicate that sustainable synthetic methanol made in this way would cost about $€ 780 /$ tonne $[8,16$, 18]. The well to tank efficiency of the process is estimated at $38 \%$, with possible improvements up to $44 \%$ using more advanced technology [15]. The use of concentrated $\mathrm{CO}_{2}$ emissions from flue gases could drop costs by $30 \%$ and achieve efficiencies of more than $50 \%$ [15]. The largest component of the process energy requirement is by far that of hydrogen production through electrolysis $[15,1]$.

A study of Specht et al. concluded that M85 (a mixture of 85 vol\% methanol and 15 vol\% gasoline) compares favourably with liquid hydrogen as a renewable transport fuel, both in terms of well-to-tank efficiency and cost of production. By mixing $15 \%$ of gasoline into methanol, the overal wellto-tank energy efficiency becomes $52,1 \%$. The cost of the atmospheric $\mathrm{CO}_{2}$ extraction and the associated energy overhead are offset against the cost of a 
hydrogen infrastructure and the energy losses through hydrogen liquefaction and distribution.

\subsection{Hydrogen versus hydrogen derived methanol: tank-to-wheel study}

Specht et al. [15] noted, however, that of greater importance to the consumer is the cost of driving a distance of $100 \mathrm{~km}$ with a passenger car. In this respect they see clear advantages for methanol, both in terms of vehicle cost and vehicle efficiency. The authors assume that the hydrogen car has the same vehicle efficiency as a gasoline car (21.4\%), but that filling and evaporation losses decrease the car's average annual efficiency to $17.9 \%$. For the methanol car Specht et al. state that flex-fuel vehicles running on M85 usually show an efficiency increase of $10 \%$ relative to gasoline, which brings the car's annual efficiency to $23.5 \%$. For a car running on neat methanol, this number can mount to $25 \%$ [15].

The efficiency figures used by Specht et al. are based on engine technology from the early 90s. Today's technology enables hydrogen and methanol engines with much improved brake thermal efficiencies. The aim of this paper is to provide a more contemporary overview of hydrogen and methanol engines and their efficiencies.

The first part of the paper reviews present and future expected technologies for both flex-fuel and dedicated hydrogen and methanol engines. The focus is on brake thermal efficiency figures reported in the literature. The second part discusses an engine efficiency comparison between gasoline, methanol and hydrogen that we performed on our own flex-fuel engine.

\section{Efficiency comparison between hydrogen, methanol and gaso- line: literature review}

The benefits and experimental research on hydrogen- and alcohol-fuelled internal combustion engines (ICEs) have been reviewed by the authors elsewhere $[6,19]$. For the sake of this paper some key points are repeated here. Properties of gasoline, hydrogen and alcohols relevant to their use in internal combustion engines are summarized in Table 1 and serve as a reference throughout the discussion. The following values may serve as a reference point for the efficiency figures mentioned in this section: modern gasoline engines achieve peak brake thermal efficiencies (BTE) of 36\%, while diesels reach $44 \%$ [20]. 


\subsection{Hydrogen as a fuel for spark-ignition engines}

Hydrogen is a very versatile engine fuel when it comes to load control. The high flame speeds of hydrogen mixtures and its wide flammability limits

(see Table 1) permit very lean operation and substantial dilution. The engine efficiency and the emission of $\mathrm{NO}_{\mathrm{x}}$ are the two main parameters used to decide between several options for the load control strategy. These include:

- Quantitative load control: using the throttle to regulate load at stoichiometric mixture conditions.

- Qualitative load control using mixture richness to regulate load at wide open throttle (WOT) and thus avoiding throttling losses.

- Qualitative load control using varying amounts of exhaust gas recirculation (EGR) to regulate load at WOT and stoichiometric mixture conditions.

Since the first and last option employ stoichiometric mixtures, normal three-way catalyst aftertreatment can be used to deal with $\mathrm{NO}_{\mathrm{x}}$ emissions. When using lean mixtures, the engine-out $\mathrm{NO}_{\mathrm{x}}$ emissions must be low enough to avoid the need for any aftertreatment. More information on these different load strategies can be found in earlier publications [6, 21].

\subsection{Reported efficiencies for hydrogen spark-ignition engines}

Finding means to maximize engine efficiency is very important for $\mathrm{H}_{2}$ ICEs considering the $\mathrm{H}_{2}$ on-board storage challenge. Several papers have reported efficiencies of engines operated on hydrogen. Ford [22, 23, 24] published figures obtained on a dedicated hydrogen engine, where (among other things) the compression ratio (CR) was optimized to take advantage of the high auto-ignition temperature of hydrogen. Tang et al. [22] mapped the brake specific fuel consumption, both for a constant equivalence ratio, throttled strategy as for a WOT strategy (regulating load with mixture richness). Brake and indicated thermal efficiencies were shown, as a function of equivalence ratio, for different compression ratios and engine speeds. The maximum indicated thermal efficiency was $52 \%$, which was for a $\lambda=3.3$ and $5000 \mathrm{rpm}$ condition. The maximum brake thermal efficiency peaked at $38 \%$, around $\lambda=2$ and $2000 \mathrm{rpm}$. Similar figures were reported by Natkin et al. [23] for a similar engine with supercharging to increase power output. The authors also report a relative increase of $15-20 \%$ in brake thermal efficiency at the lower 
loads when using the equivalence ratio to control load (WOT, qualitative control strategy) rather than throttling (quantitative control strategy).

BMW [25, 26, 27] reported efficiency figures for the different load control strategies. Berckmüller et al. [25] showed an indicated thermal efficiency map for a port fuel injected engine, including the wide open throttle strategy, throttled stoichiometric and supercharged stoichiometric strategies. Indicated thermal efficiencies reached $40 \%$ at low load and $32 \%$ at high load. They also mapped the stoichiometric EGR strategy as an alternative to the throttled stoichiometric approach, which resulted in a relative efficiency increase of roughly $5 \%$.

From the research cited above, it may be clear that port fuel injection (PFI) is the predominant mixture formation strategy for hydrogen prototype and demonstration vehicles. In an attempt to increase power levels and avoid combustion anomalies, cryogenic hydrogen injection and hydrogen direct injection (DI) have been successfully demonstrated in research settings.

Injection of cryogenic, gaseous hydrogen into the intake manifold significantly lowers the temperature, thus increasing the density of the air/fuel mixture and therefore results in a higher power output. Besides an increase in attainable power output, cryogenic injection also leads to a relatively higher efficiency in the medium and upper part-load regions of about 5\% [28].

For hydrogen direct injection the mixture stratification that results from a late injection strategy can be exploited to improve the typical trade-off between efficiency and $\mathrm{NO}_{\mathrm{x}}$ emissions. A homogeneous mixture at an equivalence ratio $\lambda \approx 1.25$ results in peak $\mathrm{NO}_{\mathrm{x}}$ emissions, whereas a stratified mixture with the same global air fuel ratio will result in lower $\mathrm{NO}_{\mathrm{x}}$ as the local equivalence ratio will be either leaner or richer than $\lambda=1.25$. A reduction of heat losses to the cylinder walls can further increase the efficiency [6].

The efficiency potential of hydrogen DI operation was recently demonstrated on a single-cylinder Ford research engine, achieving an estimated peak brake thermal efficiency of more than $45 \%$ at an engine speed of 3000 rpm [24]. Even at part-load hydrogen DI can be used for optimizing engine efficiency. A study of basic injection strategies in a single-cylinder engine showed that the combustion duration at low engine loads can be reduced with late injection, resulting in an increase in indicated thermal efficiency from $29 \%$ to more than 34\% [29]. Promising results have also been reported using hydrogen in direct injection compression ignition engines. The reader is referred to $[6,20]$ for more information on this. 


\subsection{Methanol as a fuel for spark-ignition engines}

Methanol and ethanol have the potential to increase engine performance and efficiency, even without the use of alternative load control strategies, thanks to a variety of interesting properties. These properties are more marked with methanol (being the lightest alcohol) and thus the potential for increase in power and efficiency is highest for this fuel. Still, because a lot of the recent research efforts have focused on bio-ethanol, some ethanol related work is also quoted here.

The most important favourable properties of light alcohols include (see Table 1):

- High heat of vaporization, which in combination with the low stoichiometric air to fuel ratio leads to high degrees of intake charge cooling as the injected fuel evaporates.

- Elevated knock resistance, which is partly due to the considerable cooling effect. This opens opportunities for increased power and efficiency by applying higher compression ratios, optimal spark timing and aggressive downsizing.

- High flame speeds (about 40\% higher than gasoline in comparable conditions) which enables qualitative load control using mixture richness or varing amounts of EGR.

More information on these and other properties of alcohols relevant to their use in spark-ignition engines can be found in earlier publications [30, 31]. These publications also focus on the use of alcohols in SI engines and their influence on pollutant emissions.

\subsection{Reported efficiencies for methanol spark-ignition engines}

Although on-board storage is less of an issue than for hydrogen, the lower volumetric energy content of alcohols as compared to gasoline still incites to optimize engine efficiency. The potential for increased efficiency from alcohol engines depends on whether the engine is designed for alcohol operation only or for flexible fuel operation on both gasoline and alcohol.

In dedicated alcohol engines, the elevated knock resistance can be used to raise the compression ratio (CR) to levels of $12: 1$ and above without the need for spark retarding to avoid knock. Thanks to this design change Ford was able to obtain $20 \%$ more power and 15\% higher efficiency from their 
M85 Escort model compared to its gasoline equivalent, and this was in 1981 [32]. Clemente et al. reported similar figures for a modern dedicated ethanol engine designed for the Brazilian market [33].

More recently, Nakata et al. used neat ethanol in a high compression ratio (13:1) naturally aspirated port-fuel injected SI engine [34]. They were able to run MBT (minimal spark advance for best torque) timing and found that engine torque increased by $20 \%$ compared with operation on $92 \mathrm{RON}$ gasoline. The full-load brake thermal efficiency at $2800 \mathrm{rpm}$ was $39.6 \%$ and $31.7 \%$ on E100 and gasoline respectively. Even in operating points that were not knock limited, relative efficiency improvements of over $10 \%$ were possible due to the other favorable properties of ethanol. Brusstar et al. [35] exploited the wide dilution tolerance of methanol in a production 1.9 litre turbocharged diesel engine with a CR of 19:1. The diesel injectors were replaced with injection. The high compression ratio enabled peak brake thermal efficiencies higher than the baseline diesel engine (40\%) for operation on methanol (42\%). Elevated levels of EGR (up to 50\%) were used to spread the high efficiency regions to part-load operating points. Throttle-less operation was possible down to a BMEP (brake mean effective pressure) of 6 bar.

To avoid the chicken and egg problem associated with the lack of alcohol refuelling stations, flexible fuel vehicles (FFVs) were developed during the 1980s. The lower knock resistance of gasoline meant the CR could no longer be increased a lot. Still FFVs attained about 5\% more power and efficiency due to increased volumetric efficiency, lower flow losses and more isochoric combustion [36]. Today, active knock control and aggressive spark retarding make it possible to combine high $\mathrm{CR}$ and flexible fuel operation. Pearson et al. used E85 (mixture of $85 \mathrm{vol} \%$ ethanol and gasoline) in a supercharged flexible fuel vehicle with a compression ratio of 11.5:1 [37]. Retaining optimal ignition timing increased the peak engine power by 14\% compared to RON 95 gasoline. The authors took advantage of the high degrees of charge cooling by injecting part of the fuel upstream of the supercharger, thus lowering compression work. This helped to increase the thermal efficiency by $16 \%$ at maximum torque. Bergström et al. took full advantage of the evaporative cooling effect by using E85 in a production-type turbocharged flex-fuel engine with direct injection [38]. Operation on E85 increased the engine's power by $20 \%$. The mean brake thermal efficiency over the New European Driving Cycle was improved by over $5 \%$ compared to operation on gasoline. 


\subsection{Comparison against conventional gasoline}

310 methanol show a great potential for efficiency improvements in spark-ignition engines. The achievable level of improvement depends on whether the engine is designed to run on hydrogen or methanol only (dedicated engine) or should also be able to burn gasoline (flex-fuel engine). ciencies of respectively $45 \%$ [24] and $42 \%$ [35] have been reported, compared to $36 \%$ and $42 \%$ for modern gasoline and diesel engines respectively. In part load operating conditions the ability to use high compression ratios and throttleless load control enables increases in efficiency of $10-20 \%$ relative to on gasoline, a direct comparison on the same engine is not possible. Figures published by Ford Motor Company [39] suggest, however, that the mean brake thermal efficiency of their dedicated hydrogen P2000 vehicle over a metro cycle is up to $17.9 \%$ higher than a similar gasoline vehicle.

itative load control allows improvements of $15-20 \%$ relative to gasoline for hydrogen flex-fuel vehicles in part-load [23]. Methanol flex-fuel vehicles can have the advantage of faster flames speeds in combination with reduced cooling and flow losses when running on methanol. The associated efficiency improvements of about $5 \%$ can be retained over the entire load range.

To the authors' knowledge, no direct comparisons of hydrogen, methanol and gasoline on the same engine were published. Therefore, the next section reports efficiency figures gathered on our own flex-fuel engine running on these three fuels. These could give an indication for the order of magnitude of mean efficiency values for use in tank-to-wheel studies. The engine is based on a production-type four-cylinder gasoline engine with port fuel injection. It was converted for flex-fuel operation by adding an additional port fuel injection system for hydrogen and adapting the existing gasoline injection system to be compatible with methanol. This is the easiest way to introduce 340 flex-fuel capability. The engine can thus be seen as representative for the majority of flex-fuel engines that might appear on the market. 


\section{Efficiency comparison between hydrogen, methanol and gaso- line: experimental study}

\subsection{Experimental set-up}

345

A Volvo four cylinder sixteen valve naturally aspirated gasoline engine with a total swept volume of $1783 \mathrm{cc}$ and a compression ratio of 10.3:1 with maximum power output $88 \mathrm{~kW}(120 \mathrm{HP})$ at $5800 \mathrm{rpm}$ and maximum torque $170 \mathrm{Nm}$ at $4000 \mathrm{rpm}$ was converted to tri-fuel operation by mounting an additional fuel rail supplying gaseous fuel (in this case, hydrogen) to 8 Teleflex GSI gas injectors (2 per cylinder), mounted on the intake manifold. Additional adjustments to allow reliable operation on hydrogen are described in [21]. Liquid fuel injectors with increased flow capacity and stainless steel fuel lines and fuel rail were installed to ensure methanol compatibility. The standard spark plugs were replaced by colder ones to avoid pre-ignition issues on hydrogen and methanol [37].

A MoTeC M800 engine control unit is used to control ignition timing, start of injection, injection duration and intake valve timing. Cylinder pressure measurements were possible using a spark plug pressure sensor, a piezoelectric Kistler type 6118AFD13. A piezo-resistive Kistler type 4075A10 sensor placed in the intake manifold close to the inlet valves was used for pegging the cylinder pressure. The crank angle was recorded using a Kistler crank angle encoder type COM2611.

The exhaust gas components $\mathrm{O}_{2}, \mathrm{CO}, \mathrm{CO}_{2}, \mathrm{NO}, \mathrm{NO}_{\mathrm{x}}$ and $\mathrm{H}_{2}$ are measured $\left(\mathrm{O}_{2}\right.$ : Maihak Oxor-P S710, paramagnetic; $\mathrm{CO}, \mathrm{CO}_{2}, \mathrm{NO}, \mathrm{NO}_{2}$ : Maihak Multor 610, non-dispersive infra-red; $\mathrm{H}_{2}$ : Maihak Thermor 615, thermal conductivity). Hydrogen fuel consumption was metered using a Bronkhorst In-Flow mass flow meter for gases (F-116AI-FD-00-V). For methanol and gasoline gravimetric fuel measurement was used. A direct reading of the air to fuel equivalence ratio $\lambda$ is given by a Bosch wide band sensor and digital air/fuel ratio meter with calibrations for hydrogen, methanol and gasoline.

\subsection{Experimental results and discussion: brake thermal efficiency}

This paragraph compares the brake thermal efficiency between engine operation on hydrogen, methanol and gasoline. For hydrogen, the wide open throttle (WOT) operation is used whenever possible. $\mathrm{A} \mathrm{NO}_{\mathrm{x}}$ threshold of 100 ppm was maintained, consistent with other work [21]. In earlier work the corresponding $\mathrm{NO}_{\mathrm{x}}$ threshold air to fuel equivalence ratio was determined to be $\lambda=2$ [21]. On the naturally aspirated engine used in this study, the mixture 
could not be held sufficiently lean at high loads. At these operating points throttled stoichiometric operation was preferred, so that $\mathrm{NO}_{\mathrm{x}}$ emissions could be treated in a TWC (three way catalyst) with high conversion efficiencies. For gasoline and methanol, throttled stoichiometric operation was employed for the same reason. Load control using varying amounts of residual gas could not be considered since the engine did not dispose of an external EGR circuit.

\subsubsection{Comparison at steady cruise in high gear}

To compare the distinct features of hydrogen, methanol and gasoline the measured cylinder pressure curves are compared at a single operating point: $40 \mathrm{Nm}$ and $1500 \mathrm{rpm}$. This would correspond to a low load, steady cruise in high gear. Table 2 shows the engine settings and resulting brake thermal efficiency (BTE) for four points: hydrogen WOT, hydrogen throttled $(\lambda=1)$, methanol and gasoline. Figure 1 shows the corresponding diagrams of cylinder pressure versus volume, in logarithmic coordinates.

From the left graph in Figure 1 it is clear that the hydrogen WOT strategy should be preferred above the throttled stoichiometric approach where possible, as pumping losses are very low. Flow losses are not negligible though, because of the high air flow associated with lean operation. Throttled hydrogen operation produces efficiencies comparable to what is achievable on methanol or gasoline (see Table 2). This is due to several opposing factors. On the one hand the higher stoichiometric burning velocity and corresponding (almost) constant volume combustion (see Figure 1-a) are favourable. The BTE further benefits from a lower required air flow to achieve a certain torque, resulting in lower flow losses compared to gasoline operation. Although the stoichiometric AFR (air to fuel ratio) of hydrogen exceeds that of gasoline, its higher lower heating value results in a higher mixture energy per unit mass of air and thus less required air flow to achieve a certain torque (see Table 1). The pumping losses are further reduced by the larger throttle opening for hydrogen (see Table 2). The low vapour density (low molecular weight) of hydrogen results in a reduced volumetric (molar) mixture energy density compared to stoichiometric gasoline-air mixtures and consequently in a larger throttle opening to achieve the same amount of trapped mass (see Table 1). On the other hand, the cooling losses on stoichiometric hydrogen operation can be a multiple of those on fossil fuels. This is caused by various particular properties of hydrogen [40]. Due to these massive cooling losses the BTE at $\lambda=1$ is almost $20 \%$ lower relative to WOT operation. This is in 
line with the values reported by Sierens et al. [40].

When comparing the pressure traces for methanol and gasoline (Figure 1-b), it can be seen that operation on methanol takes advantage of its higher burning velocity. The flow losses on methanol operation are slightly lower than for gasoline. On the one hand the airflow on methanol operation is lower due to the lower mixture energy per unit mass of air. On the other hand the throttle opening on methanol operation is smaller. Although the volumetric (molar) mixture energy content is smaller than for gasoline, the large charge cooling upon methanol injection results in a substantial increase in volumetric efficiency. Consequently the throttle opening to achieve a certain torque is smaller on methanol than on gasoline, which increases throttling losses.

\subsubsection{Comparison at varying engine load and speed}

Next, the efficiencies on hydrogen, methanol and gasoline operation were compared at different torque settings (20, 40 and $80 \mathrm{Nm}$ - equivalent to 1.41, 2.82 and 5.64 BMEP) and for a range of engine speeds. The influence of gas dynamics (flow losses) is expected to rise with increasing rpm. At each point, MBT spark-timing was used.

Figure 2-a and Figure 3-a show the brake thermal efficiency as a function of engine speed, for fixed torque outputs of $20 \mathrm{Nm}$ and $40 \mathrm{Nm}$ respectively. Three BTE curves are shown. One for hydrogen with WOT where the corresponding equivalence ratios are given in Figures 2-b and 3-b. The other two curves are for gasoline and methanol operation for which the corresponding throttle position is given in Figures 2-b and 3-b.

From Figures 2-a and 3-a, it is clear that at low loads, the BTE on hydrogen is much higher than on gasoline and methanol (20-40\% higher relative to gasoline). This difference is mostly due to the absence of throttling losses and the lean mixtures of hydrogen (reduced cooling losses, higher theoretical efficiency). The BTE for hydrogen decreases with engine speed due to higher flow losses in the intake manifold. Despite the absence of throttling, the flow losses in WOT operation can be quite substantial due to the elevated airflow.

To compensate for these higher losses more hydrogen needs to be injected, which can be seen from the $\lambda$ curves.

From Figure 2 and Figure 3 it can be observed that the BTE on methanol is $10 \%$ higher relative to gasoline. This is partly explained by the higher burning velocity of methanol, which can be more than twice that of gasoline. As mentioned before, another contributing factor is the reduced flow loss on methanol due to lower airflow. This advantage is partly lost however 
because of the smaller throttle opening. The in-cylinder cooling losses are also smaller on methanol compared to gasoline operation. Not only does the charge cooling due to methanol evaporation reduce the unburned mixture temperature, but the high heat capacity of burned methanol also reduces the flame and exhaust gas temperatures compared to gasoline. This results in lower cooling losses.

The mean exhaust temperatures when operating on hydrogen, methanol or gasoline at 20 and $40 \mathrm{Nm}$ are shown in Figure 4. The exhaust temperatures on methanol are about $20-50{ }^{\circ} \mathrm{C}$ lower than on gasoline. The exhaust gases on hydrogen are much cooler due to important dilution with air. As the air dilution decreases when switching from $20 \mathrm{Nm}$ (a) to $40 \mathrm{Nm}$ (b) the corresponding exhaust temperatures rise. Apart from those mentioned above, minor factors contributing to the BTE rise on methanol might be a slight increase in expansion work due to a higher mole ratio of products to reactants (see Table 1) and an elevated theoretical efficiency due to the higher ratio of $C_{p}$ to $C_{v}$.

Both for methanol and gasoline the BTE drops with increasing engine speed. The elevated airflow at higher engine speed causes higher flow losses. This is partly compensated by the larger throttle openings at higher engine speeds, but the net effect is a decrease in BTE.

In Figure 2 and Figure 3 the air to fuel equivalence ratio $\lambda$ for the $\mathrm{H}_{2}$ WOT case is always higher than 2 and as a result the $\mathrm{NO}_{\mathrm{x}}$ emissions are very low (see further, Figure 6). As mentioned above, this is a result of the low temperatures during lean combustion (see also Figure 4). Figure 5 shows the BTE as a function of engine speed for a fixed torque output of $80 \mathrm{Nm}$. As can be seen from the $\lambda$ curve on the right, the hydrogen WOT measurements at this load have an air to fuel equivalence ratio below the $\mathrm{NO}_{\mathrm{x}}$ threshold value of 2. As a consequence these points cannot be part of a practical load control strategy since they result in unacceptable $\mathrm{NO}_{\mathrm{x}}$ emissions. Pressure charging might be used to keep the mixture sufficiently lean at these higher loads $[6,41]$. On the naturally aspirated engine used in this study, however, throttled stoichiometric hydrogen operation is considered at this load. The efficiency penalty caused by the $\mathrm{NO}_{\mathrm{x}}$ boundary condition can be seen by comparing the BTE curves for hydrogen WOT and hydrogen $\lambda=1$ operation, showing an absolute decrease in BTE of about 5\%. As mentioned earlier the vast cooling losses at stoichiometric hydrogen operation result in brake thermal efficiencies that are barely higher than on gasoline. In Figure 5 there are no values for the $\mathrm{H}_{2} \lambda=1$ case at $4500 \mathrm{rpm}$. This condition could not be 
set because of backfire occurrence.

Comparing Figures 2, 3 and 5, the efficiencies of gasoline, methanol and hydrogen can be seen to increase as the delivered torque increases. The explanation differs slightly for hydrogen and the two other fuels. In the three cases, as a result of the increasing torque, the mechanical efficiency increases strongly. For gasoline and methanol, the flow losses across the throttle valve increase because of the larger flow, although this is slightly compensated by a larger throttle opening. The increase in mechanical efficiency is clearly the dominating effect. In the case of hydrogen, the flow losses decrease because of a smaller air flow since more air is displaced by hydrogen as a result of the richer mixture. This also leads to a decreased influence of engine speed on the hydrogen BTEs: from Figures 2, 3 and 5 it can be seen that as the load increases, the BTE decreases less strongly with engine speed.

\subsection{Experimental results and discussion: pollutant emissions}

Although the main focus of this paper is on the brake thermal efficiency, some emissions measurement results have been included to highlight the influence of the different fuels on the production of noxious emissions and since pollutant emissions represent an important constraint for efficiency optimization.

Figure 6 compares the engine-out $\mathrm{NO}_{\mathrm{x}}$ emissions for hydrogen, methanol and gasoline at a low load (20 Nm, a) and a higher load (80 Nm, b). At low loads the $\mathrm{NO}_{\mathrm{x}}$ emissions on hydrogen WOT operation can be seen to be below the $\mathrm{NO}_{\mathrm{x}}$ threshold of $100 \mathrm{ppm}$. The lean burn strategy and the associated low combustion temperatures (see Figure 4) are responsible for this since most $\mathrm{NO}_{\mathrm{x}}$ is produced by the thermal mechanism which is very dependent on temperature. Cooler combustion temperatures also explain the lower $\mathrm{NO}_{\mathrm{x}}$ figures on methanol compared to on gasoline. For these fuels, the strong influence of engine speed on the amount of $\mathrm{NO}_{\mathrm{x}}$ emissions at $20 \mathrm{Nm}$ might be caused by elevated levels of internal EGR at low rpm. At this low load, the vacuum in the intake due to throttling is quite considerable, so internal EGR levels can be expected to be important. At $80 \mathrm{Nm}$ the internal EGR levels are much lower, which explains the higher $\mathrm{NO}_{\mathrm{x}}$ emissions for gasoline and methanol. At this higher load it can be seen that the hydrogen WOT strategy exceeds the $\mathrm{NO}_{\mathrm{x}}$ threshold. The $\mathrm{H} 2 \lambda=1$ case and its associated elevated burning temperatures produce even more $\mathrm{NO}_{\mathrm{x}}$, but these can be treated in a TWC with high conversion efficiencies. 
Figure 7 compares the engine-out CO emissions for gasoline and methanol. Those for hydrogen are negligible and can only originate from burnt oil. It can be seen that the emissions are slightly lower for methanol. According to some authors this is due to the oxygenated nature of methanol which might cause a more complete combustion [42]. However, slight deviations from stoichiometric operation might have much more influence on the $\mathrm{CO}$ emissions.

Emissions of unburned hydrocarbons have not been included since flame ionization detectors (as used in our measurements) are reported to have a slow response time to oxygenated species $[43,44]$. Oxygenated species such as unburned methanol and formaldehyde are commonly found in the exhaust gases of methanol engines. Using a flame ionization detector might thus lead to an underestimation of the total unburned hydrocarbons on methanol operation.

\section{Conclusions}

From well to tank studies it appears that hydrogen derived methanol represents an interesting alternative to liquid or compressed hydrogen, both in terms of production cost and energy efficiency. Existing well to wheel studies employ engine efficiency data based on outdated technology, leading to an underestimation of the potential of these fuels. For example, Specht et al. [15] assume that the mean efficiency of hydrogen and gasoline fuelled cars are comparable, whereas methanol allows a relative efficiency increase of $10 \%$. This paper tried to give an overview of state-of-the-art hydrogen and methanol-fuelled engines and their efficiencies.

${ }_{550}$ Both fuels offer a great potential for efficiency improvements compared to gasoline engines thanks to a variety of favourable properties. However, there is a clear distinction between engines specifically designed for hydrogen or methanol operation and flex-fuel engines, which should also run on gasoline.

For dedicated engines, the literature indicates that peak brake thermal efficiencies up to $45 \%$ and $42 \%$ are possible on hydrogen and methanol respectively. By way of comparison: modern gasoline engines achieve peak BTEs of $36 \%$, while diesels reach $44 \%$. In part load, the ability to employ qualitative load control instead of throttling enables relative efficiency improvements between 10-20\% due to reduced pumping losses.

The potential of flex-fuel engines was investigated on a production-type naturally aspirated four-cylinder spark-ignition engine with port fuel-injection, 
which was converted to run on gasoline, methanol and hydrogen. Operation on hydrogen using qualitative load control enabled the highest efficiencies, especially at low loads, where improvements up to $40 \%$ relative to gasoline to throttled stoichiometric operation, resulting in efficiencies comparable to those on gasoline.

The efficiency benefit of methanol is more modest (5-10\% relative to gasoline), but can be retained over the entire load range. These improvements a slight decrease in cooling losses. Reduced combustion temperatures on methanol also cause a considerable reduction (30\% and beyond) in engineout $\mathrm{NO}_{\mathrm{x}}$ emissions.

As opposed to existing well-to-wheel studies, future studies should take

should also distinguish between dedicated and flex-fuel engines. Future work will focus on obtaining quantitative data for the cycle averaged efficiencies of modern hydrogen and methanol engines.

\section{Acknowledgements}

580 ship (FWO09/ASP/030 and FWO11/ASP/056) of the Research Foundation - Flanders (FWO). The Research Foundation - Flanders has also funded the experimental equipment (1.5.147.10N). The authors would like to thank BioMCN for providing the neat bio-methanol used in this study and Interreg

South Netherlands.

\section{References}

[1] Pearson R, Turner J, Eisaman M, Littau K. Extending the supply of alcohol fuels for energy security and carbon reduction. SAE International; 2009. SAE paper no. 2009-01-2764.

[2] Agency IE. World Energy Outlook 2006. Paris: IEA Head of Publications Service; 2006.

[3] Bossel U. Does a hydrogen economy make sense? Proc IEEE 2006;94(10):1826-37. 
[14] Stucki S, Schuler A, Constantinescu M. Coupled co2 recovery from the atmosphere and water electrolysis: Feasibility of a new process for hydrogen storage. Int J Hydrogen Energ 1995;20(8):653-63. 
[15] Specht M, Staiss F, Bandi A, Weimer T. Comparison of the renewable transportation fuels, liquid hydrogen and methanol, with gasolineenergetic and economic aspects. Int J Hydrogen Energ 1998;23(5):38796.

[16] Mignard D, Sahibzada M, Duthie JM, Whittington HW. Methanol synthesis from flue-gas co2 and renewable electricity: a feasibility study. Int J Hydrogen Energ 2003;28(4):455-64.

[17] Olah G, Goeppert A, Prakash G. Beyond Oil and Gas: the Methanol Economy. Weinheim, Germany: Wiley-VCH Verlag CmbH \& Co.KGaA; 2006.

[18] Specht M, Bandi A, Elser M, Staiss F, Inui T, Anpo M, et al. Comparison of co2 sources for the synthesis of renewable methanol. In: Studies in Surface Science and Catalysis; vol. Volume 114. Elsevier; 1998, p. 363-6.

[19] Vancoillie J, Verhelst S. Modeling the combustion of light alcohols in SI engines: a preliminary study. In: FISITA 2010 World Automotive Congress. Budapest, Hungary; 2010, p. 1-12.

[20] Verhelst S, Wallner T, Eichlseder H, Naganuma K, Gerbig F, Boyer B, et al. Electricity powering combustion: Hydrogen engines. Proc IEEE 2012;100(2):427-39.

[21] Verhelst S, Maesschalck P, Rombaut N, Sierens R. Efficiency comparison between hydrogen and gasoline, on a bi-fuel hydrogen/gasoline engine. Int J Hydrogen Energ 2009;34(5):2504-10.

[22] Tang X, Kabat DM, Natkin. RJ, Stockhausen WF, Heffel J. Ford p2000 hydrogen engine dynamometer development. SAE International; 2002. SAE paper no. 2002-01-0242.

[23] Natkin RJ, Tang X, Boyer B, Oltmans B, Denlinger A, Heffel JW. Hydrogen ic engine boosting performance and nox study. SAE International; 2003. SAE paper no. 2003-01-0631.

[24] Welch A, Mumford D, Munshi S, Holbery J, Boyer B, Younkins M, et al. Challenges in developing hydrogen direct injection technology for internal combustion engines. SAE International; 2008. SAE paper no. 2008-01-2379. 
[25] Berckmüller M, Rottengruber H, Eder A, Brehm N, Elsässer G, MüllerAlander $\mathrm{G}$, et al. Potentials of a charged si-hydrogen engine. SAE International; 2003. SAE paper no. 2003-01-3210.

[26] Rottengruber H, Berckmüller M, Elsässer G, Brehm N, Schwarz C. A high-efficient combustion concept for direct injection hydrogen internal combustion engine. In: World hydrogen energy conference. Yokohama, Japan; 2004, .

[27] Eichlseder H, Wallner T, Freymann R, Ringler J. The potential of hydrogen internal combustion engines in a future mobility scenario. SAE International; 2003. SAE paper no. 2003-01-2267.

[28] Heller K, Ellgas S. Optimization of hydrogen internal combustion engine with cryogenic mixture formation. In: 1st Int Symp on Hydrogen Internal Combustion Engines. Graz, Austria; 2006, p. pp. 49-58.

[29] Wallner T, Nande A, Naber J. Study of basic injection configurations using a direct-injection hydrogen research engine. SAE International; 2009. SAE Paper No. 2009-01-1418.

[30] Vancoillie J, Verhelst S, Demuynck J. Laminar burning velocity correlations for methanol-air and ethanol-air mixtures valid at SI engine conditions. SAE International; 2011. SAE paper no. 2011-01-0846.

[31] Pearson R, Turner J, Peck A. Gasoline-ethanol-methanol tri-fuel vehicle development and its role in expediting sustainable organic fuels for transport. In: IMechE Low Carbon Vehicles Conference. London, UK; 2009, p. 1-21.

[32] Nichols R. The methanol story: a sustainable fuel for the future. J Sci Ind Res 2003;62(January-February):97-105.

[33] Clemente RC, Werninghaus E, Coelho EPD, Ferraz LAS. Development of an internal combustion alcohol-fueled engine. SAE International; 2001. SAE paper no. 2001-01-3917.

[34] Nakata K, Utsumi S, Ota A, Kawatake K, Kawai T, Tsunooka T. The effect of ethanol fuel on a spark ignition engine. SAE International; 2006. SAE paper no. 2006-01-3380. 
[35] Brusstar MJ, Stuhldreher M, Swain D, Pidgeon WM. High efficiency and low emissions from a port-injected engine with neat alcohol fuels. SAE International; 2002. SAE paper no. 2002-01-2743.

[36] McCoy GA, Kerstetter J, Lyons JK. Alcohol-fueled vehicles. Tech. Rep. WSE-93/25; Washington State Energy Office; 1993.

[37] Pearson R, Turner J, Holland B, Peck R. Alcohol-based fuels in high performance engines. SAE International; 2007. SAE paper no. 2007-010056 .

[38] Bergström K, Nordin H, Konigstein A, Marriot CD, Wiles MA. Abc - alcohol based combustion engines - challenges and opportunities. In: 16th Aachener Kolloquium Fahrzeug- und Motorentechnik. Aachen; 2007, p. 1031-72.

[39] Szwabowski SJ, Hashemi S, Stockhausen WF, Natkin RJ, Reams L, Kabat DM, et al. Ford hydrogen engine powered p2000 vehicle. SAE International; 2002. SAE paper no. 2002-01-0243.

[40] Sierens R, Demuynck J, Paepe MD, Verhelst S. Heat transfer comparison between methane and hydrogen in a spark ignited engine. In: World Hydrogen Energy Conference 2010. Essen, Germany; 2010, p. 1-6.

[41] Wallner T, Matthias NS, Scarcelli R. Influence of injection strategy in a high-efficiency hydrogen direct injection engine. SAE International; 2011. SAE paper no. 2011-01-2001.

[42] Turner D, Xu H, Cracknell RF, Natarajan V, Chen X. Combustion performance of bio-ethanol at various blend ratios in a gasoline direct $710 \quad$ injection engine. Fuel 2011;90(5):1999-2006.

[43] Wallner T. Correlation between speciated hydrocarbon emissions and flame ionization detector response for gasoline/alcohol blends. J Eng Gas Turbines Power 2011;133(8):1-8.

[44] Sandstroem-Dahl C, Erlandsson L, Gasste J, Lindgren M. Measurement methodologies for hydrocarbons, ethanol and aldehyde emissions from ethanol fuelled vehicles. SAE International; 2010. SAE paper no. 201001-1557. 


\section{List of Tables}

1 Properties of typical gasoline, methanol, ethanol and hydrogen relevant to internal combustion engines $[6,19,31] . *$ Includes atmospheric nitrogen. NA: not available. NTP: normal temperature $(293 \mathrm{~K})$ and pressure $(101325 \mathrm{~Pa}) . \quad$. . . . . . . . . . 23

2 Efficiency comparison of hydrogen, methanol and gasoline at $1500 \mathrm{rmp}$ and $40 \mathrm{Nm}$. . . . . . . . . . . . . 23

\section{List of Figures}

1 Cylinder pressure versus cylinder volume at $1500 \mathrm{rpm}$ and 40 Nm for (a) hydrogen WOT and $\lambda=1$ and (b) gasoline and methanol . . . . . . . . . . . . . . . . 24

2 Brake thermal efficiency as a function of engine speed, for a fixed brake torque of $20 \mathrm{Nm}$. . . . . . . . . . . . . . 25

3 Brake thermal efficiency as a function of engine speed, for a fixed brake torque of $40 \mathrm{Nm}$. . . . . . . . . . . . . . . . 26

4 Mean exhaust temperatures as a function of engine speed, for a fixed brake torque of $20 \mathrm{Nm}$ (a) and $40 \mathrm{Nm}$ (b) . . . . . . . 27

5 Brake thermal efficiency as a function of engine speed, for a fixed brake torque of $80 \mathrm{Nm}$. . . . . . . . . . . . . . . . . . . 28

6 Engine-out $\mathrm{NO}_{\mathrm{x}}$ emissions as a function of engine speed, for a fixed brake torque of $20 \mathrm{Nm}$ (a) and $80 \mathrm{Nm}$ (b) . . . . . . . . 29

7 Engine-out CO emissions as a function of engine speed, for a fixed brake torque of $20 \mathrm{Nm}$ (a) and $80 \mathrm{Nm}$ (b) . . . . . . . 30 
Table 1: Properties of typical gasoline, methanol, ethanol and hydrogen relevant to internal combustion engines $[6,19,31] .{ }^{*}$ Includes atmospheric nitrogen. NA: not available. NTP: normal temperature (293 K) and pressure (101325 Pa).

\begin{tabular}{lllll}
\hline Property & Gasoline & Methanol & Ethanol & Hydrogen \\
\hline Chemical Formula & Various & $\mathrm{CH}_{3} \mathrm{OH}$ & $\mathrm{C}_{2} \mathrm{H}_{5} \mathrm{OH}$ & $\mathrm{H}_{2}$ \\
Oxygen Content by Mass [\%] & 0 & 50 & 34.8 & 0 \\
Density at NTP [kg/l] & 0.74 & 0.79 & 0.79 & 0.00008 \\
Lower Heating Value [MJ $/ \mathrm{kg}]$ & 42.9 & 20.09 & 26.95 & 120 \\
Volumetric Energy Content [MJ/1] & 31.7 & 15.9 & 21.3 & 0.010 \\
Stoichiometric Air to Fuel Ratio $[\mathrm{kg} / \mathrm{kg}]$ & 14.7 & 6.5 & 9 & 34.2 \\
Energy per Unit mass of air [MJ $/ \mathrm{kg}]$ & 2.95 & 3.12 & 3.01 & 3.51 \\
Research Octane Number $(\mathrm{RON})$ & 95 & 109 & 109 & $130(\lambda=2.5)$ \\
Motor Octane Number $(\mathrm{MON})$ & 85 & 88.6 & 89.7 & $\mathrm{NA}$ \\
Sensitivity $(\mathrm{RON}-\mathrm{MON})$ & 10 & 20.4 & 19.3 & $\mathrm{NA}$ \\
Boiling point at 1 bar $\left[{ }^{\circ} \mathrm{C}\right]$ & $25-215$ & 65 & 79 & -253 \\
Heat of vaporisation $[\mathrm{kJ} / \mathrm{kg}]$ & $180-350$ & 1100 & 838 & 461 \\
Reid Vapour Pressure $[\mathrm{psi}]$ & 7 & 4.6 & 2.3 & $\mathrm{NA}$ \\
Mole ratio of products to reactants* & 0.937 & 1.061 & 1.065 & 0.852 \\
Flammability Limits in Air $[\lambda]$ & $0.26-1.60$ & $0.23-1.81$ & $0.28-1.91$ & $0.15-10.57$ \\
Laminar flame speed at NTP, $\lambda=1[\mathrm{~cm} / \mathrm{s}]$ & 28 & 42 & 40 & 210 \\
Adiabatic Flame Temperature $\left[{ }^{\circ} \mathrm{C}\right]$ & 2002 & 1870 & 1920 & 2117 \\
Specific $\mathrm{CO}_{2}$ Emissions $[\mathrm{g} / \mathrm{MJ}]$ & 73.95 & 68.44 & 70.99 & 0.00 \\
\hline
\end{tabular}

Table 2: Efficiency comparison of hydrogen, methanol and gasoline at $1500 \mathrm{rmp}$ and $40 \mathrm{Nm}$

\begin{tabular}{lllll}
\hline & Hydrogen WOT & Hydrogen $\lambda=\mathbf{1}$ & Methanol & Gasoline \\
\hline$\lambda$ & 2.57 & 1 & 1 & 1 \\
Throttle position (TP) [\%] & 100 & 21 & 8.5 & 14 \\
Ignition timing [ ${ }^{\circ} \mathrm{ca}$ BTDC] & 10 & -7 & 17 & 25 \\
Mass Air Flow [g/s] & 22 & 9.1 & 9.4 & 10.3 \\
BTE [\%] & 29.9 & 24.1 & 26.1 & 24.0 \\
\hline
\end{tabular}




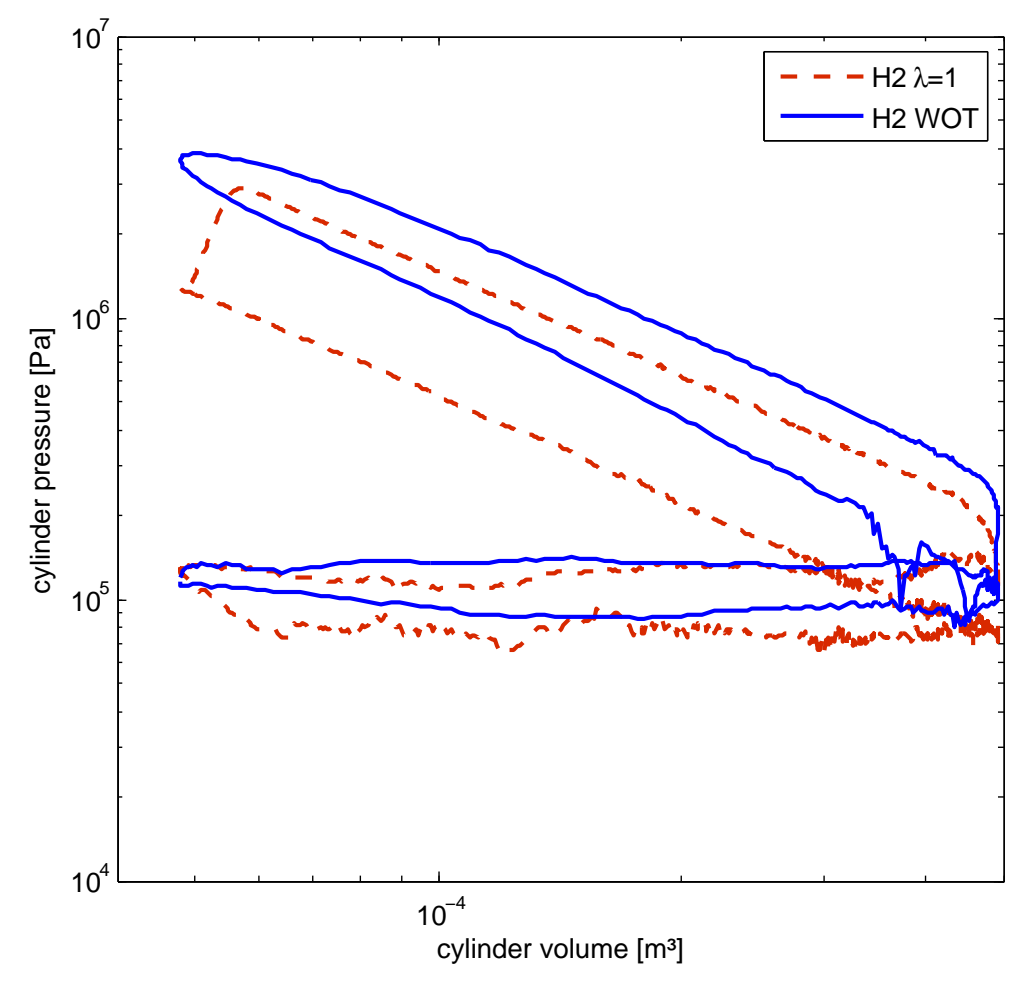

(a) hydrogen WOT and $\lambda=1$

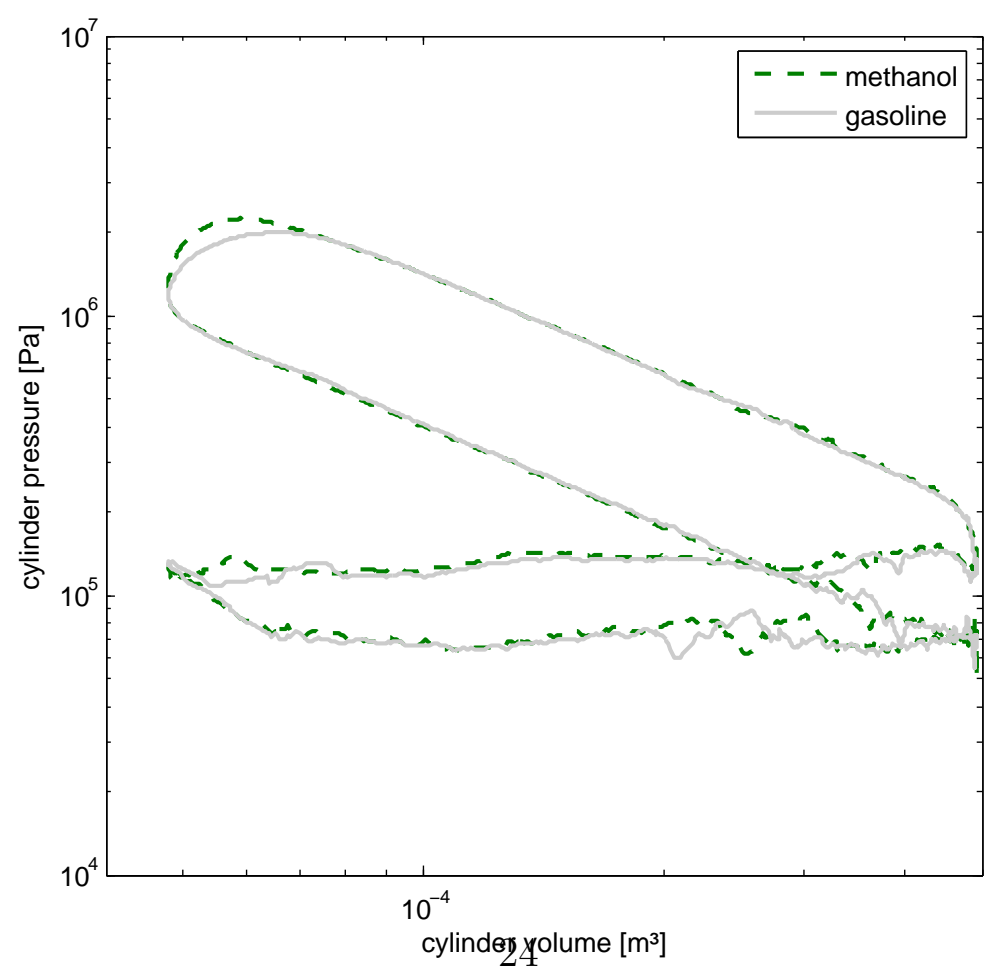

(b) gasoline and methanol

Figure 1: Cylinder pressure versus cylinder volume at $1500 \mathrm{rpm}$ and $40 \mathrm{Nm}$ for (a) hydrogen WOT and $\lambda=1$ and (b) gasoline and methanol 


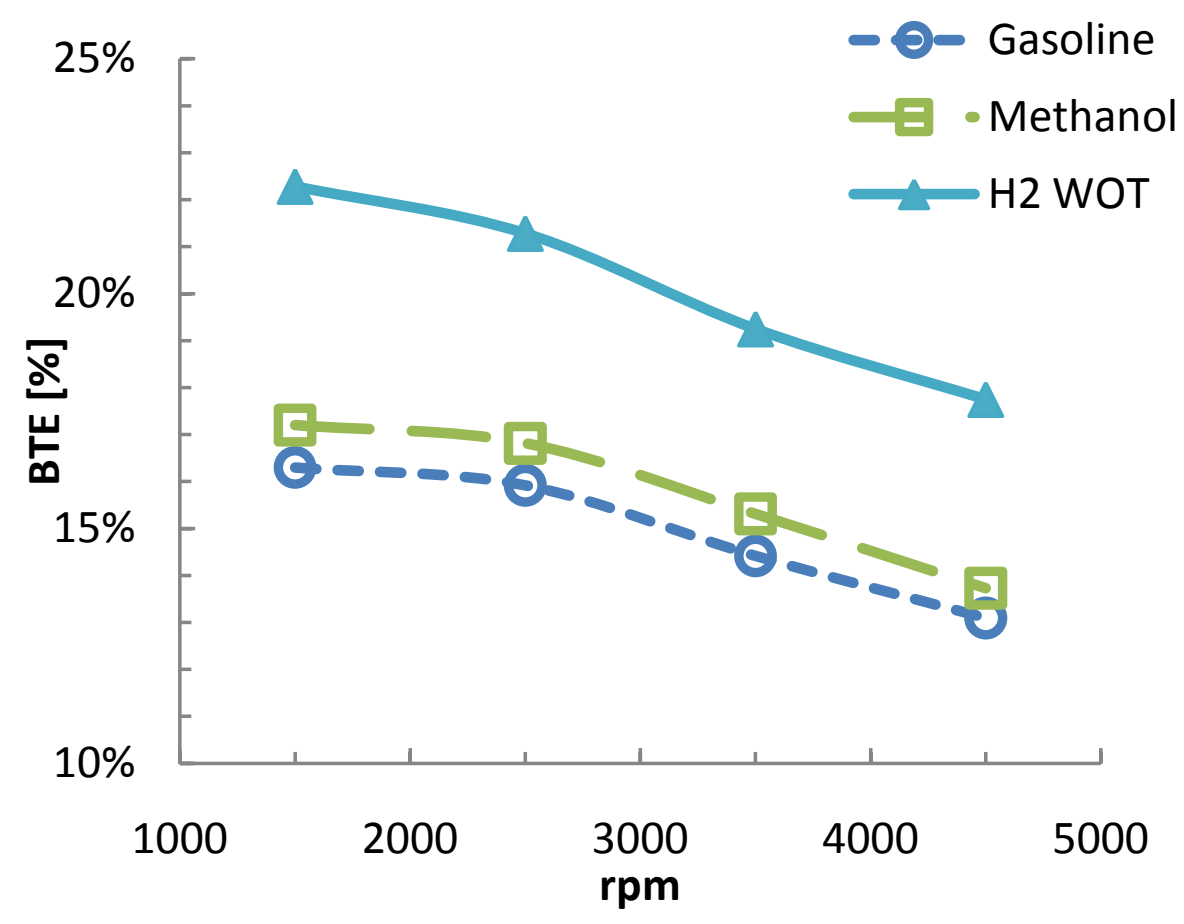

(a) BTE

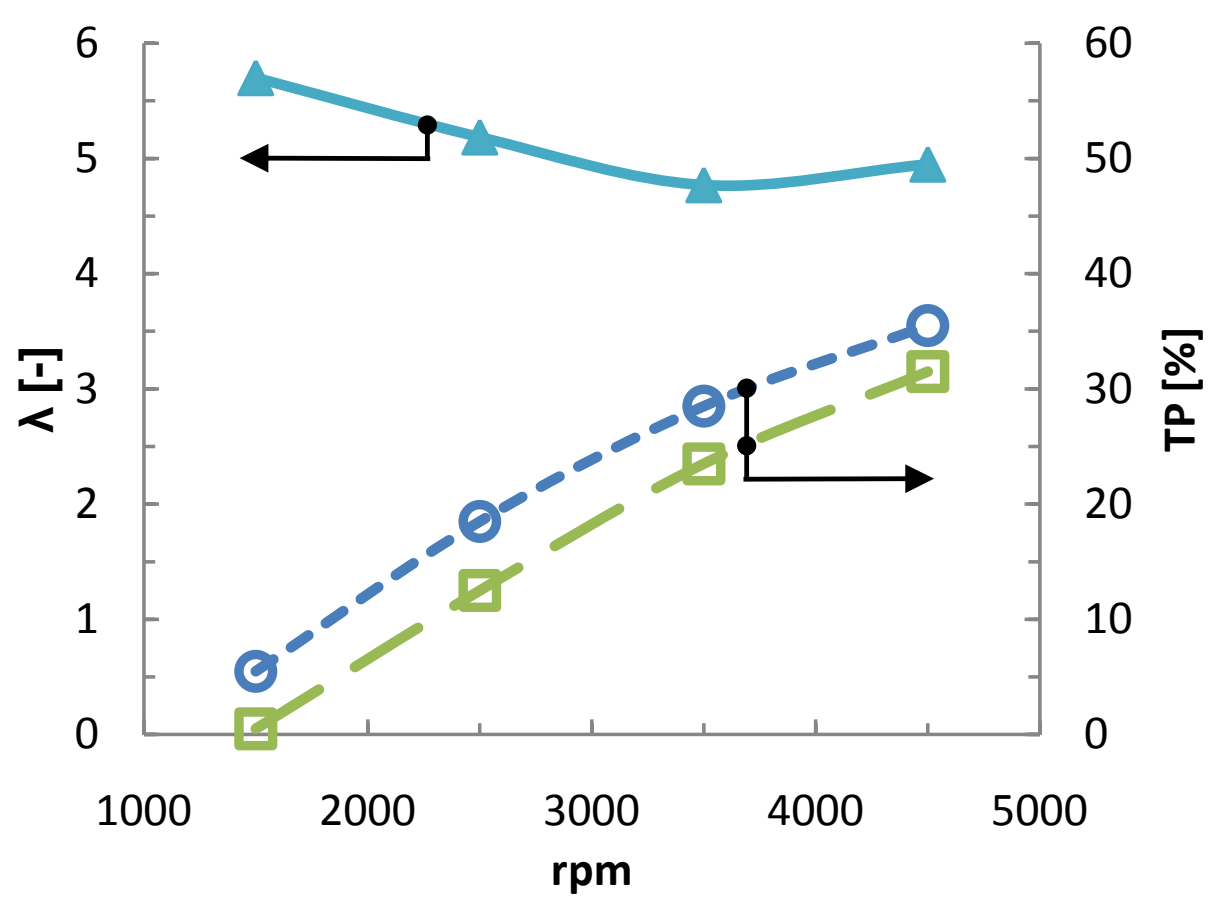

(b) $\lambda$ and throttle position

Figure 2: Brake thermal efficiency as a function of engine speed, for a fixed brake torque of $20 \mathrm{Nm}$ 


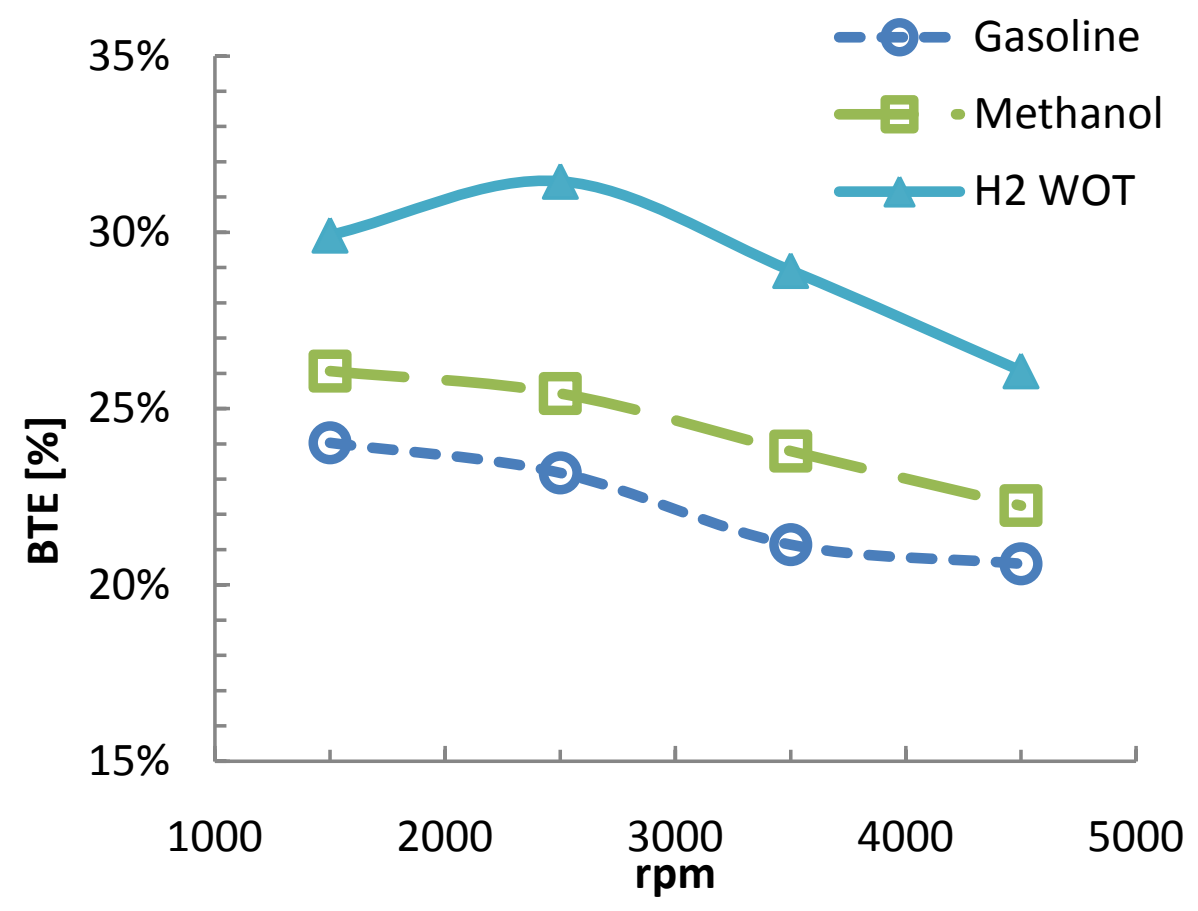

(a) BTE

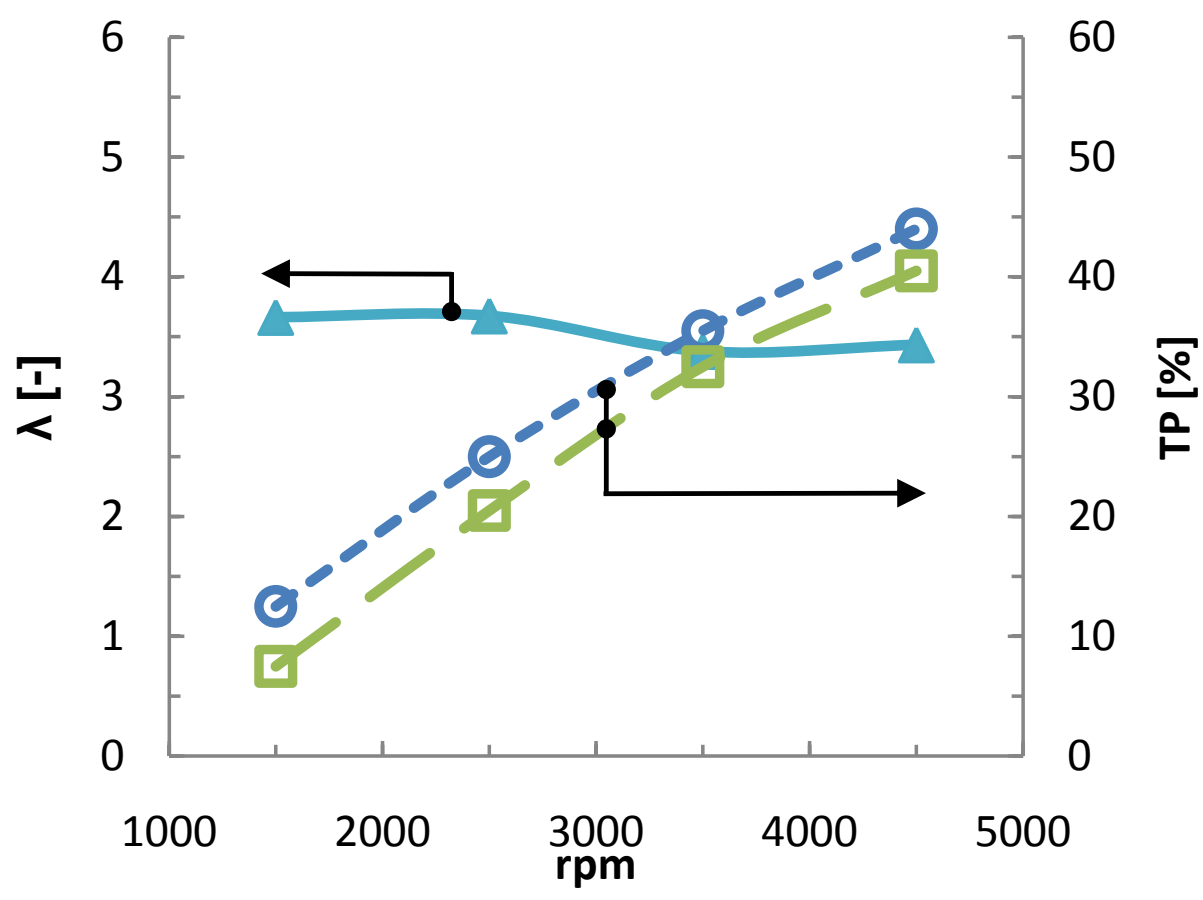

(b) $\lambda$ and throttle position

Figure 3: Brake thermal efficiency as a function of engine speed, for a fixed brake torque of $40 \mathrm{Nm}$ 


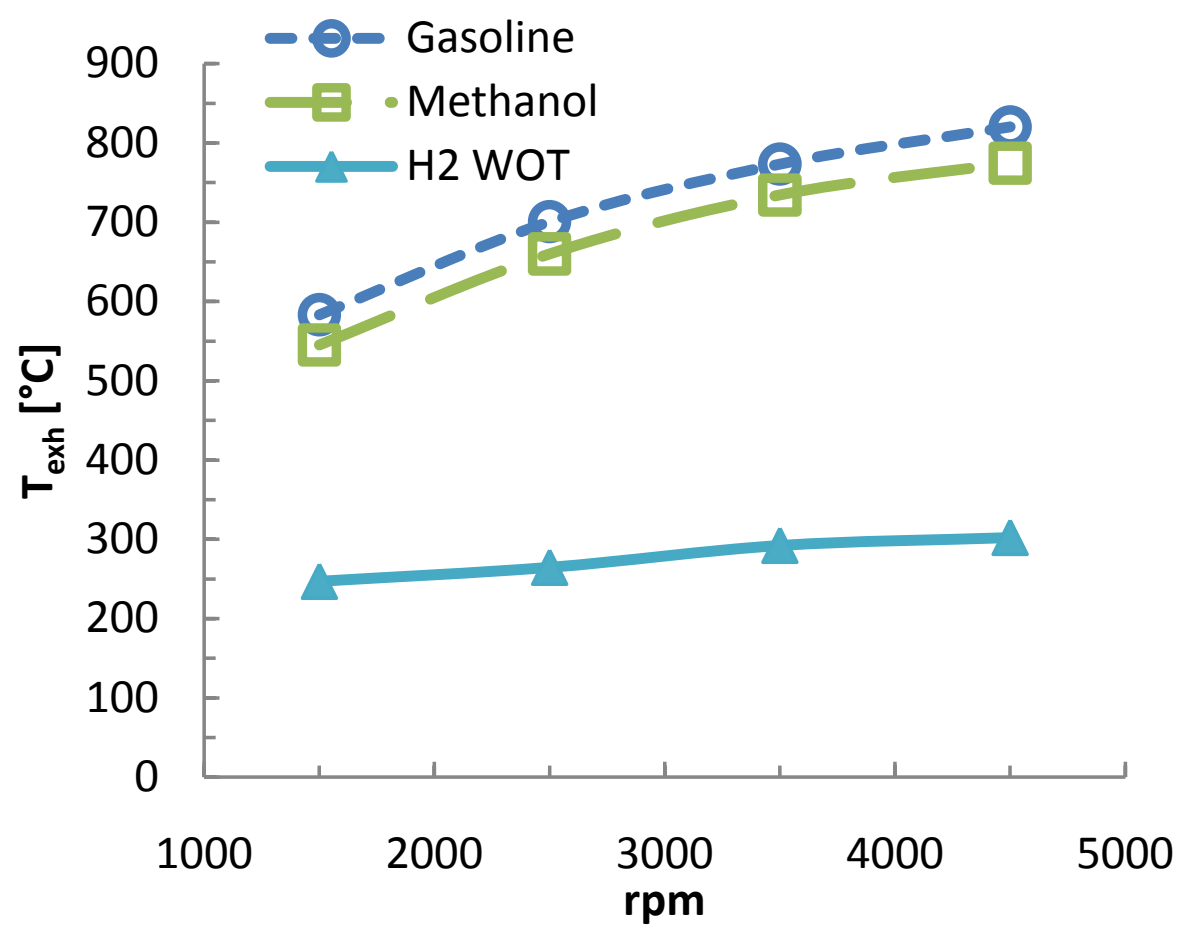

(a) $20 \mathrm{Nm}$

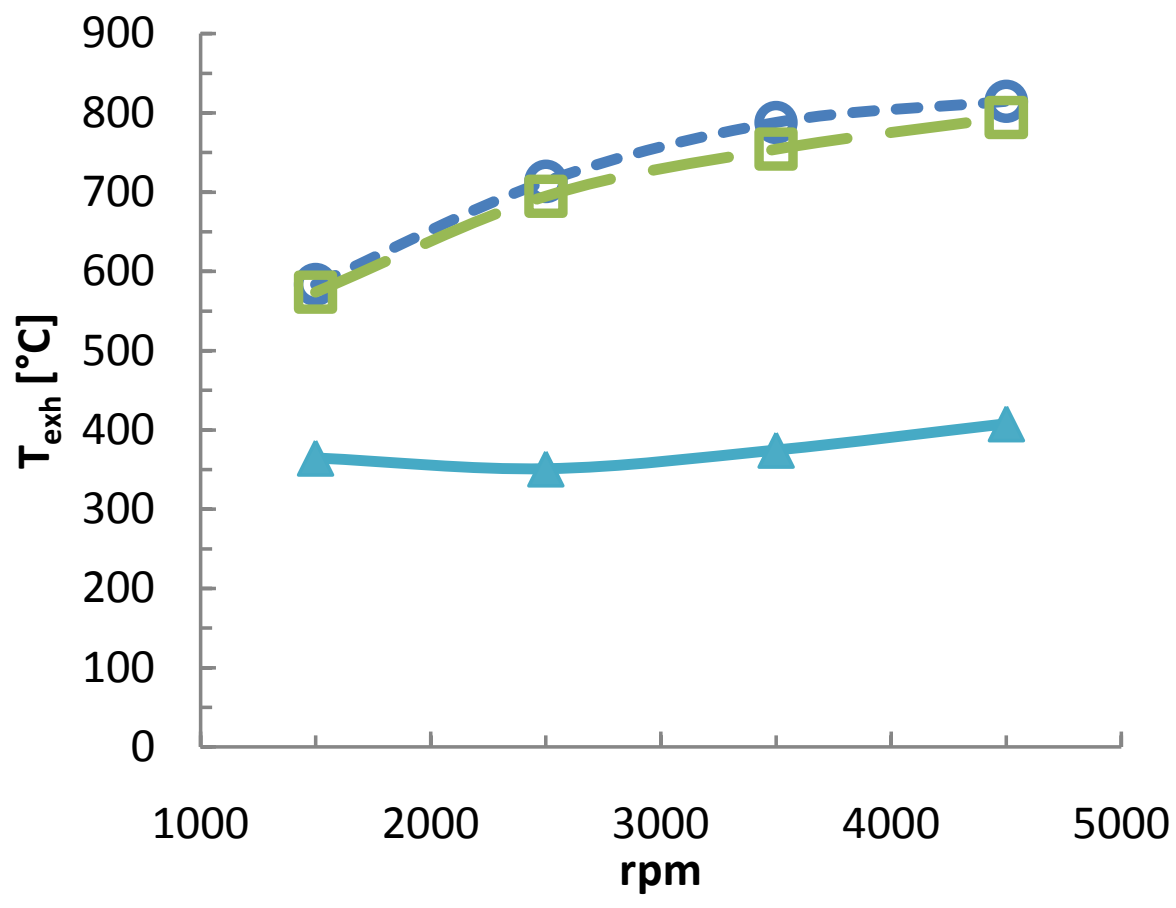

(b) $428 \mathrm{Nm}$

Figure 4: Mean exhaust temperatures as a function of engine speed, for a fixed brake torque of $20 \mathrm{Nm}$ (a) and $40 \mathrm{Nm}$ (b) 


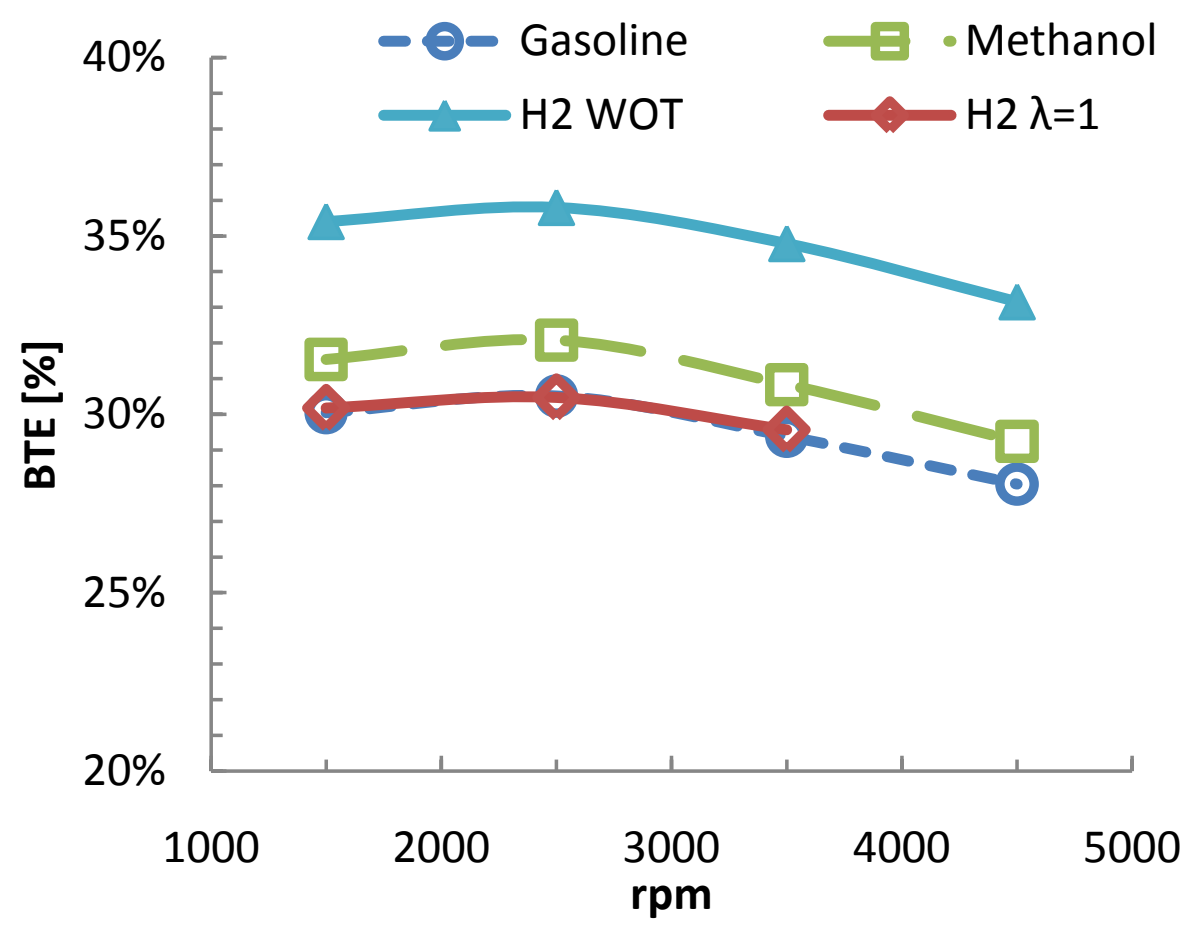

(a) BTE

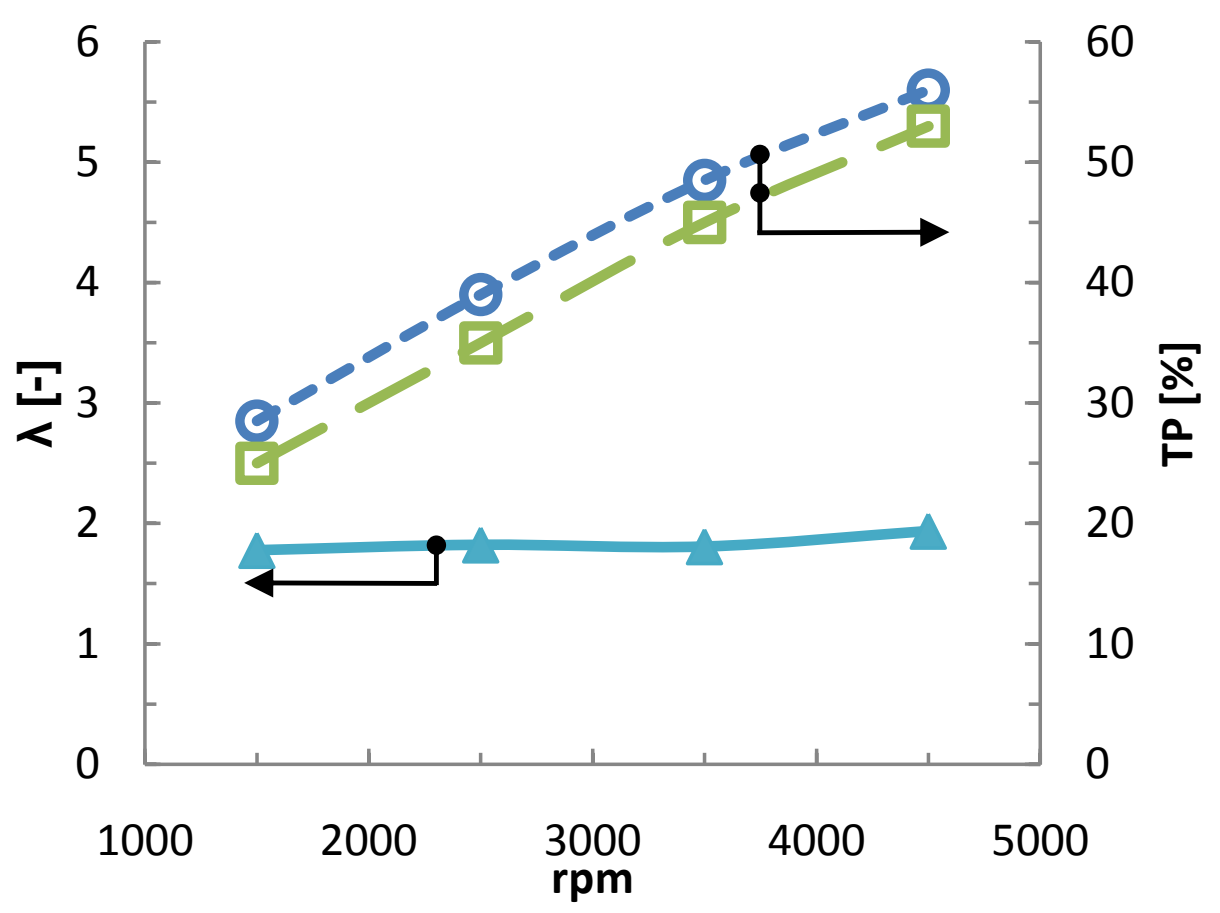

(b) $\lambda$ and thestle position

Figure 5: Brake thermal efficiency as a function of engine speed, for a fixed brake torque of $80 \mathrm{Nm}$ 


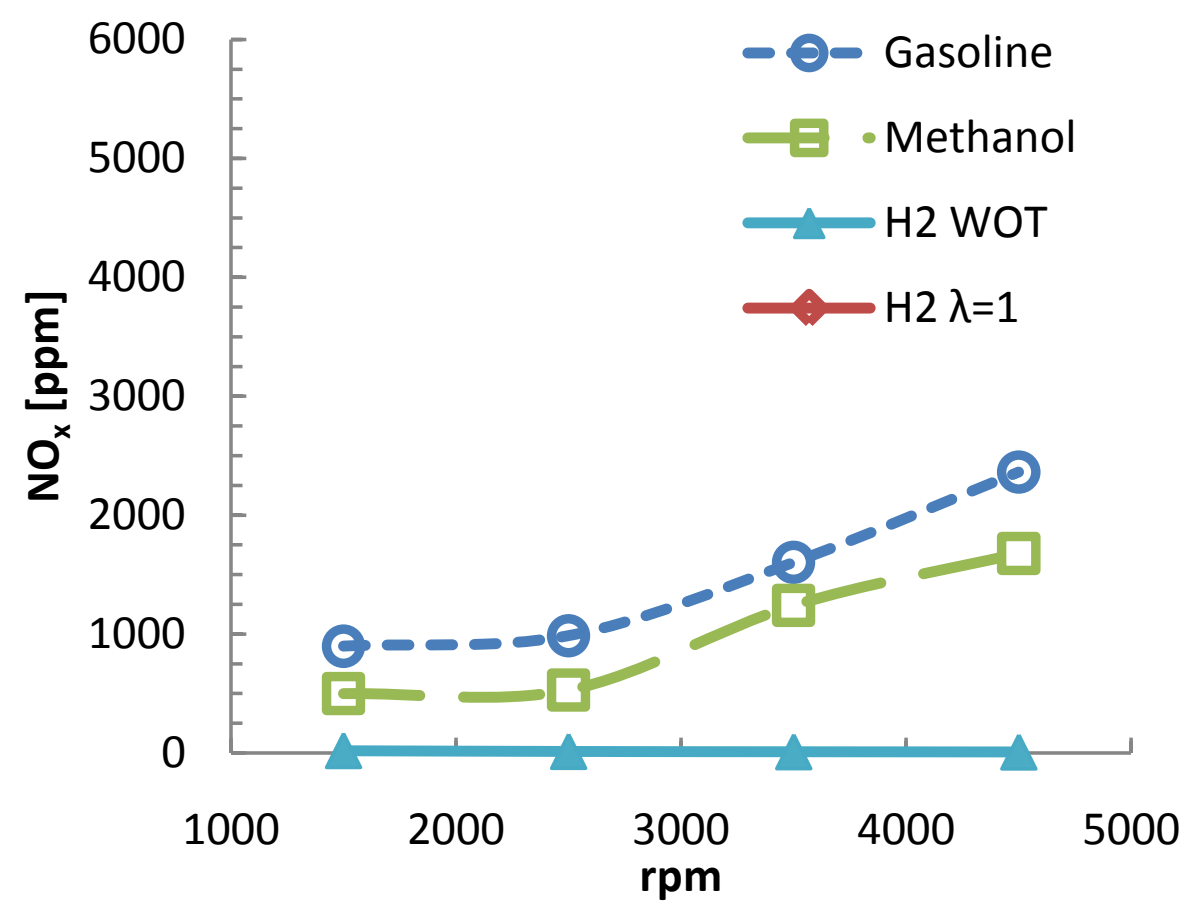

(a) $20 \mathrm{Nm}$

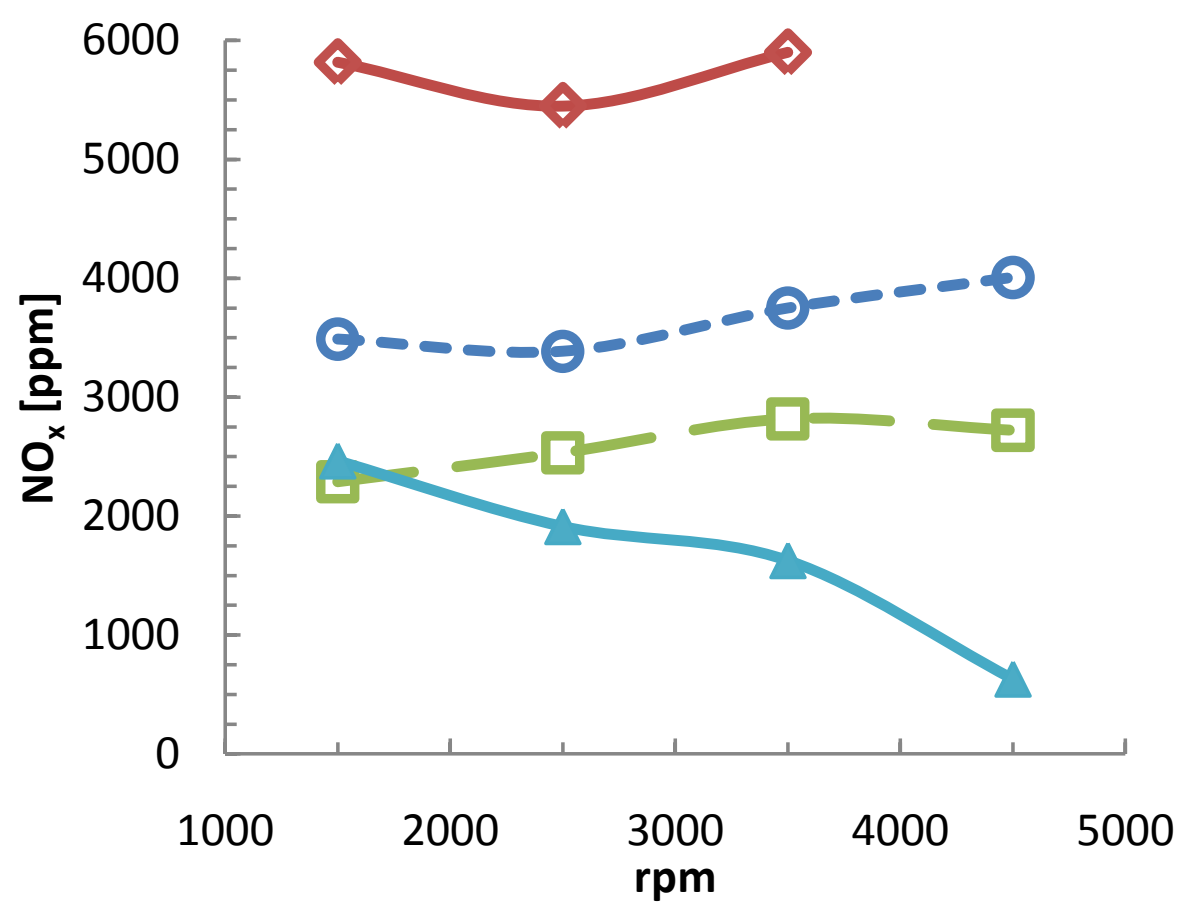

(b) $829 \mathrm{Nm}$

Figure 6: Engine-out $\mathrm{NO}_{\mathrm{x}}$ emissions as a function of engine speed, for a fixed brake torque of $20 \mathrm{Nm}$ (a) and $80 \mathrm{Nm}$ (b) 


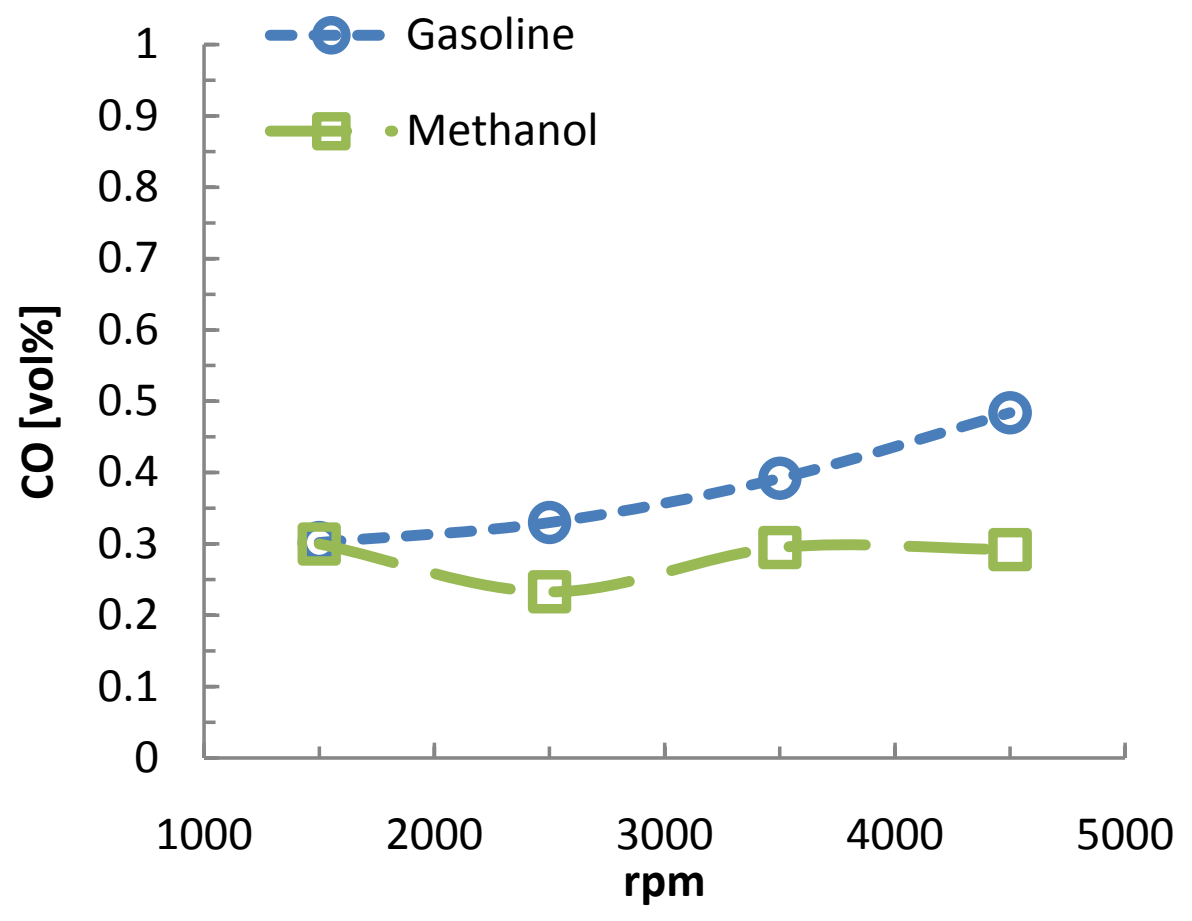

(a) $20 \mathrm{Nm}$

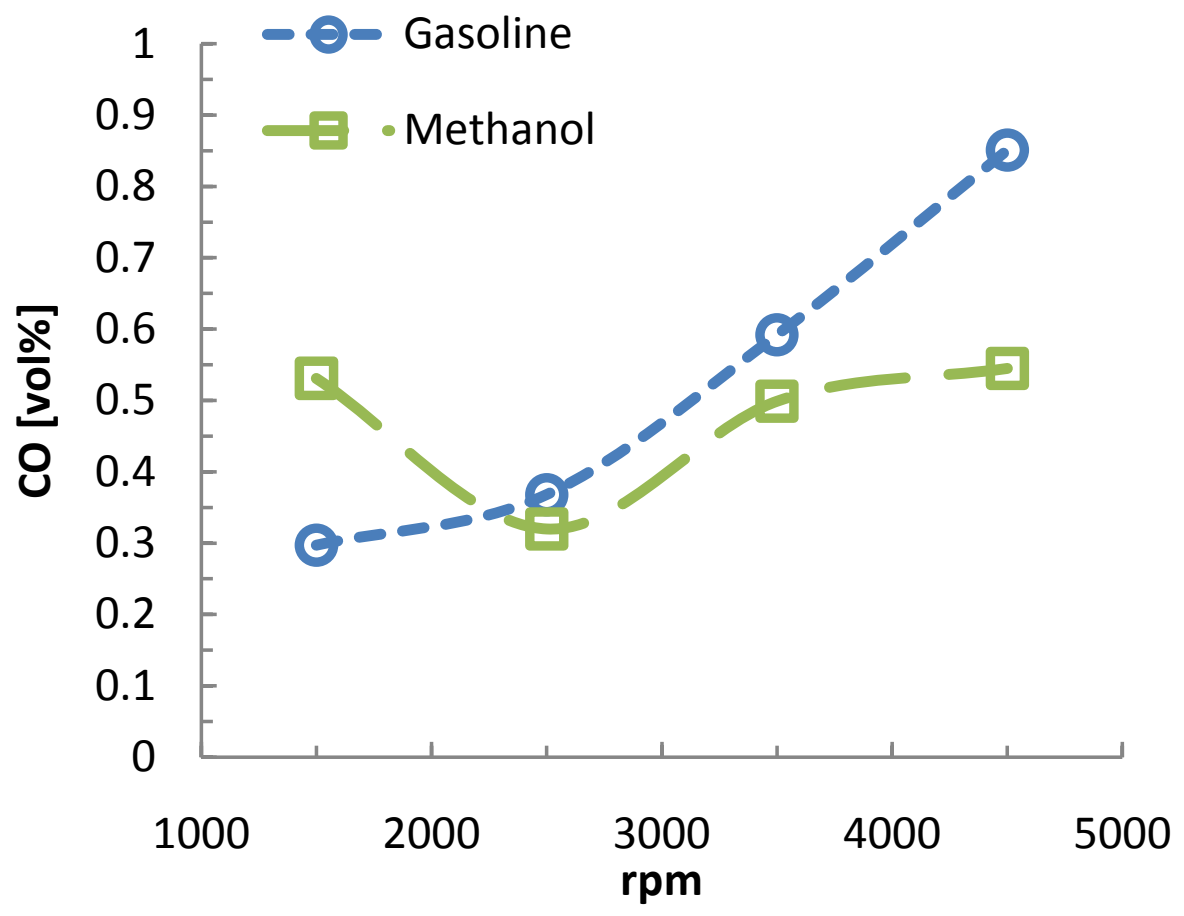

(b) $830 \mathrm{Nm}$

Figure 7: Engine-out CO emissions as a function of engine speed, for a fixed brake torque of $20 \mathrm{Nm}$ (a) and $80 \mathrm{Nm}$ (b) 